\title{
Pelaksanaan Terhadap Promosi Dan Evaluasi Kesehatan Untuk Meningkatkan Budaya Keselamatan Pasien Di Rumah Sakit
}

\author{
Selly Febi Margaretha Panggabean \\ sellyfebi2601@gmail.com
}

\section{LATAR BELAKANG}

Rumah sakit sebagai organisasi badan usaha di bidang kesehatan mempunyai peranan penting dalam mewujudkan derajat kesehatan dan keselamatan masyarakat secara optimal. Oleh karena itu rumah sakit dituntut agar mampu mengelola kegiatannya dengan mengutamakan pada tanggung jawab para professional di bidang kesehatan, khususnya tenaga medis dan tenaga keperawatan dalam menjalankan tugas dan kewenangannya. Tidak selamanya layanan medis yang diberikan oleh tenaga kesehatan dapat memberikan hasil yang sebagaimana diharapkan semua pihak. Berdasarkan Undang-Undang No. 44 Tahun 2009 Tentang Rumah Sakit, Rumah sakit dikembangkan untuk meningkatkan kemampuan setiap orang agar bisa mengendalikan dan memperbaiki kesehatan dirinya serta menjadikan rumah sakit sebagai tempat kerja yang sehat. Hal ini bertujuan untuk menjamin dan menjaga keselamatan hidup pasien, staf, pengunjung dan masyarakat. Rumah sakit dalam meningkatkan mutu pelayanan memerlukan standar untuk memaksimalkan proses pelayanan melalui Promosi Kesehatan Rumah Sakit (PKRS) (Depkes RI, 2011).

Promosi kesehatan mempunyai pengertian dan arti yang sangat relevan. Pengertian promosi kesehatan adalah proses memberdayakan atau memandirikan masyarakat untuk memelihara, meningkatkan dan melindungi kesehatannya melalui peningkatan kesadaran, kemauan dan kemampuan, serta pengembangan lingkungan yang sehat. Promosi kesehatan mencakup aspek perilaku, yaitu upaya untuk memotivasi, mendorong dan membangkitkan kesadaran akan potensi yang dimiliki masyarakat agar mereka mampu memelihara dan meningkatkan kesehatannya (Notoatmodjo, 2010). Pentingnya promosi kesehatan di rumah sakit 
karena efektivitas suatu pengobatan, selain dipengaruhi oleh pola pelayanan kesehatan yang ada, sikap dan keterampilan para unit PKRS, juga sangat dipengaruhi oleh lingkungan, sikap, pola hidup pasien, dan keluarga pasien serta tergantung pada tingkat kerja sama yang positif antara personel kesehatan dengan pihak pasien beserta keluarganya. Di dalam proses keperawatan, evaluasi merupakan tahap akhir yang bertujuan untuk menilai apakah tindakan keperawatan yang telah dilakukan tercapai atau tidak untuk mengatasi suatu masalah. (Meirisa, 2013). Pada tahap evaluasi, perawat dapat mengetahui seberapa jauh diagnosa keperawatan, rencana tindakan, dan pelaksanaan telah tercapai. Pada prinsipnya, evaluasi promosi kesehatan sama dengan evaluasi kesehatan lainnya, karakteristiknya ialah dalam indikator yang disamping memakai indikator epidemiologik sebagai indikator dampak seperti upaya kesehatan lainnya, dalam mengukur efek, lebih menggunakan indikator perilaku.

Penilaian mutu rumah sakit didapatkan melalui sistem akreditasi, salah satunya adalah sasaran keselamatan pasien karena telah menjadi prioritas untuk layanan kesehatan di seluruh dunia (Join Commission International, 2015; Cosway, Stevens, \& Panesar, 2012). Patient safety (keselamatan pasien) merupakan komponen vital dan penting dalam asuhan serta langkah untuk memperbaiki mutu layanan yang berkualitas (Findyartini et al, 2015; Cahyono S.B, 2008). Salah satu langkah memperbaiki mutu pelayanan melalui penerapan budaya keselamatan pasien di rumah sakit baik pemerintah maupun swasta. Keselamatan pasien tidak lepas dari kode etik yang dijalankan oleh tenaga medis, seperti perawat. Perilaku perawat dalam pelayanan kesehatan dipengaruhi oleh berbagai macam faktor yang berkontribusi terhadap terjadinya insiden keselamatan pasien, salah satunya menurut Safety Attitudes Questionnaire (SAQ) Sexton et al (2006) ada 6 domain yang di nilai yaitu; Team work climate, safety climate, kepuasan kerja, stres, persepsi manajemen, dan lingkungan kerja. Profesionalisme keperawatan menjadi kontrak sosial antara profesi keperawatan dengan masyarakat. Masyarakat telah memberikan kepercayaan kepada perawat, sehingga perawat harus melaksanakan tugasnya dengan memberikan standar kompetensi yang tinggi dan tanggung jawab moral yang baik. Oleh karena itu, perawat memiliki tanggung jawab terhadap keselamatan dan keamanan pasien selama berada di rumah sakit. 


\section{METODE}

Dalam kajian ini, metode yang digunakan adalah literature review, yaitu dengan cara membaca, menganalisis, dan mengambil kesimpulan dalam sebuah kajian literature review yang berkaitan dengan materi pembelajaran tentang pelaksanaan terhadap promosi dan evaluasi kesehatan untuk meningkatkan budaya keselamatan pasien di rumah sakit. Adapun tinjauan literature review yang digunakan yaitu kajian jurnal online, textbook, e- book, dan sumber kajian (literature review) lainnya yang berkaitan dengan judul materi pembelajaran tersebut. Selanjutnya data yang telah dibaca, kemudian dianalisis dan disimpulkan dapat digunakan sebagai bahan pengambilan keputusan dalam menanggulangi permasalahan. Dengan menggunakan jurnal dan referensi, yang digunakan pada literature review ini dengan tahun terbit paling lama tahun 2012, dengan jumlah minimal 10 referensi literature.

\section{HASIL}

Berdasarkan hasil yang dapat dianalisis dari berbagai sumber (literature review) bahwa adanya pengaruh - pengaruh yang berhubungan dalam pelaksanaan promosi kesehatan untuk peningkatan budaya keselamatan pasien (patient safety). Adapun hasil penelitian dari berbagai sumber (literature review) yang telah dibaca dan dianalisis, maka didapati kesimpulan hasil penelitian dari sumber kajian (literature review) menunjukkan yaitu bahwa :

Standar PKRS yang telah dikembangkan dan dapat menjadi acuan dalam penyusunan instrumen akreditasi rumah sakit yang berhubungan dengan promosi kesehatan. Maka dari itu, penting dilakukan analisa pemenuhan standar PKRS. Dalam sumber kajian (literature review) yang telah di analisis didapati acuan yang digunakan dalam penelitian kajian tersebut yaitu standar PKRS oleh Pusat Promosi Kesehatan tahun 2011 dan didukung dengan Juknis PKRS tahun 2014 sesuai Keputusan Menteri Kesehatan Republik Indonesia No. 004/Menkes/SK/II/2012. Adapun didapati 5 standar acuan pada hasil sumber kajian (literature review) yaitu : (1) Kebijakan manajemen (2) Kajian kebutuhan masyarakat rumah sakit (3) Pemberdayaan masyarakat rumah sakit (4) Kemitraan (5) Tempat kerja yang aman, bersih dan sehat. 
Berdasarkan hasil observasi yang didapati pada sumber kajian (literature review) menurut Juknis PKRS tahun 2014 pada standar acuan menjelaskan bahwa :

- Pada substandar acuan yang pertama yaitu ; pada kebijakan manajemen harus memiliki kebijakan tertulis tentang PKRS.

- Pada substandar yang kedua dari acuan yang pertama adalah rumah sakit membentuk unit kerja PKRS.

- Pada substandar yang ketiga dan keempat dari acuan yang pertama adalah rumah sakit memiliki tenaga pengelola PKRS dan rumah sakit memiliki alokasi anggaran untuk pelaksanaan kegiatan PKRS.

- Substandar yang kelima dari acuan yang pertama adalah rumah sakit memiliki perencanaan kegiatan secara berkala.

- Substandar yang keenam dari acuan yang pertama adalah rumah sakit memiliki sarana atau peralatan untuk pelaksanaan PKRS.

- Substandar yang ketujuh dari acuan yang pertama adalah rumah sakit mensosialisasikan PKRS ke seluruh jajaran rumah sakit.

- Substandar yang kedelapan dari acuan yang pertama adalah rumah sakit meningkatkan kapasitas tenaga pengelola PKRS.

- Substandar yang kesembilan dari acuan yang pertama adalah rumah sakit melaksanakan pemantauan dan evaluasi pelaksanaan PKRS.

Kemudian pada budaya keselamatan pasien, terdapat hasil yang telah dianalisis dari sumber kajian (literature review), didapati faktor - faktor yang berpengaruh terhadap peningkatan keselamatan pasien dirumah sakit yaitu :

(1) Iklim Organisasi;

(2) Tingkat Pengetahuan;

(3) Penerapan Keselamatan Pasien;

(4) Aspek Komunikasi;

(5) Aspek Etika. 
Dari beberapa sumber kajian (literature review) yang telah dianalisis, didapati kesimpulan dari hasil sebuah sumber kajian yakni dari; metode seperti pengkajian, perencanaan, implementasi, monitoring dan evaluasi pelaksanaan promosi kesehatan baik untuk pasien, staf dan masyarakat rumah sakit, bahwa didalam tugas pokok dan fungsi PKRS tersebut terdapat wewenang PKRS yaitu tentang menyelenggarakan promosi kesehatan dengan prinsip koordinatif, integratif, kerjasama internal dan antar personal, hal ini berkaitan dengan kemitraan yang sudah dilaksanakan.

Pada paragraf selanjutnya, akan di bahas hasil penelitian dari berbagai sumber kajian (literature review) yang telah dianalisis dan mengacu mengarah kepada topik hasil kajian yakni; pada standar PKRS yang berhubungan dengan promosi kesehatan serta faktor - faktor yang mempengaruhi peningkatan keselamatan pasien dirumah sakit.

\section{PEMBAHASAN}

Promosi kesehatan di Rumah Sakit telah diselenggarakan sejak tahun 1994 dengan nama Penyuluhan Kesehatan Masyarakat Rumah Sakit (PKMRS). Seiring dengan perkembangannya pada tahun 2003, istilah PKMRS berubah menjadi Promosi Kesehatan Rumah Sakit (PKRS). Berbagai kegiatan telah dilakukan untuk pengembangan PKRS. Kegiatan yang dilakukan antara lain meliputi penyusunan pedoman PKRS, advokasi dan sosialisasi PKRS kepada direktur rumah sakit pemerintah, pelatihan PKRS, pengembangan dan distribusi media serta pengembangan model PKRS (Kemenkes, 2010). PKRS berusaha mengembangkan pengertian pasien, keluarga, dan pengunjung rumah sakit tentang penyakit dan pencegahannya (Depkes RI, 2010). Selain itu, PKRS juga berusaha menggugah kesadaran dan minat pasien, keluarga, dan pengunjung rumah sakit untuk berperan secara positif dalam usaha penyembuhan dan pencegahan penyakit. Namun demikian pelaksanaan PKRS dalam kurun waktu lebih dari 15 tahun belum memberikan hasil yang maksimal dan berkesinambungan. Hal ini disebabkan pada kuat atau tidaknya komitmen direktur rumah sakit dalam menjaga pelaksanaan PKRS dengan baik. Kemudian pada pelaksanaan PKRS di rumah sakit seharusnya ada acuan untuk melihat sudahkah terpenuhinya standar promosi kesehatan yang ada di rumah sakit. Hal ini berkaitan dengan akreditasi rumah sakit dan juga kepuasan pasien dan lainnya. 
Berdasarkan hal tersebut, beberapa hal strategis yang berkaitan dengan PKRS, yaitu: (1) PKRS dijadikan rumah sakit sebagai salah satu kebijakan upaya pelayanan kesehatan di rumah sakit, (2) Rumah sakit memberikan hak pasien untuk mendapatkan informasi tentang pencegahan dan pengobatan yang berhubungan dengan penyakitnya, (3) Rumah sakit mewujudkan tempat kerja yang aman, bersih dan sehat, (4) Rumah sakit menggalang kemitraan untuk meningkatkan upaya pelayanan yang bersifat preventif dan promotif.

- Standar acuan PKRS oleh Pusat Promosi Kesehatan tahun 2011 dan didukung dengan Juknis PKRS tahun 2014 sesuai Keputusan Menteri Kesehatan Republik Indonesia No. 004/Menkes/SK/II/2012 :

\section{Kebijakan Manajemen}

Pada standar acuan ini, upaya promosi kesehatan di rumah sakit harus dilakukan pada tim PKRS dan juga dilakukan oleh perawat dan dokter. Tim PKRS di rumah sakit harus memiliki perencanaan untuk kegiatan promosi kesehatan secara berkala, baik setiap minngu, bulan, dan tahun. Selain itu unit PKRS juga harus melaksanakan kewajibannya dengan sosialisasi mengenai perencanaan kegiatan promosi kesehatan ke seluruh jajaran rumah sakit. Tujuan dari pembahasan ini ialah adanya dukungan kebijakan untuk pelaksanaan PKRS sebagai bagian integral peningkatan kualitas manajemen organisasi di rumah sakit.

\section{Kajian Kebutuhan Masyarakat Rumah Sakit}

Rumah sakit harus menyediakan instrumen berupa; instrumen kajian kebutuhan pasien, keluarga pasien, serta pengunjung rumah sakit. Instrumen kebutuhan pasien terdapat pada dokumen rekam medik pasien, sedangkan kajian kebutuhan untuk keluarga pasien dan pengunjung rumah sakit dapat dilihat melalui kertas saran yang nanti dimasukkan ke dalam kotak saran sebagai bahan untuk evaluasi rumah sakit. Tim PKRS di rumah sakit juga harus selalu melakukan koordinasi dengan tenaga kesehatan lain untuk menentukan kegiatan promosi kesehatan yang akan dilakukan. Oleh karena itu, tim PKRS memiliki peran sebagai otak/perancang dari kegiatan promosi kesehatan, namun semua ide atau rancangan dari tim PKRS juga harus dikoordinasikan oleh tenaga 
kesehatan lainnya, sehingga dapat disimpulkan bahwa kajian kebutuhan masyarakat di rumah sakit berasal dari adanya koordinasi internal antara tim PKRS dengan tenaga kesehatan lainnya yang berasal dari hasil evaluasi setiap selesai melakukan kegiatan promosi kesehatan. Rumah Sakit juga harus memiliki kegiatan promosi kesehatan bagi pasien, keluarga pasien, pengunjung serta masyarakat sekitar rumah sakit yang tercantum dalam Rencana Kerja Anggaran Tahunan (RKAT).

Tujuan dari pembahasan ini ialah untuk memperoleh gambaran mengenai informasi yang dibutuhkan pasien, keluarga pasien, pengunjung rumah sakit, serta masyarakat sebagai dasar pelaksanaan promosi kesehatan.

\section{Pemberdayaan Masyarakat Rumah Sakit}

Rumah sakit harus memberikan kebutuhan informasi secara jelas terhadap kondisi pasien mengenai pengobatan, perawatan serta faktor penyebab lain yang mempengruhi kondisi pasien. Informasi tersebut bisa diberikan melalui komunikasi secara langsung kepada pasien setelah diperiksa, serta menyediakan media berupa X-banner, poster, atau leaflet mengenai suatu penyakit. Kegiatan ini dilakukan oleh staf PKRS, dokter dan juga perawat di rumah sakit. Tujuan dari pembahasan ini ialah untuk meningkatkan daya serta peran masyarakat rumah sakit dalam mencengah dan/atau mengatasi masalah tentang kesehatan yang dihadapi.

\section{Kemitraan}

Tim PKRS di rumah sakit penting untuk menjalin kerja sama kepada lembaga - lembaga ataupun ormas guna untuk menunjang jalannya promosi kesehatan di rumah sakit. Tujuan dari pembahasan ini ialah agar terjalinnya kerja sama dengan mitra terkait optimalisasi pelaksanaan kegiatan PKRS.

\section{Tempat kerja yang Aman, Bersih dan Sehat.}

Tim PKRS di rumah sakit harus selalu bekerjasama dengan tim manajemen rumah sakit, untuk selalu menjaga sarana prasarana lingkungan rumah sakit beserta kelengkapannya baik dalam maupun luar gedung sehingga kawasan rumah sakit akan tampak terlihat rapi, bersih, 
dan nyaman. Tujuan dari pembahasan ini ialah untuk mewujudkan tempat kerja yang bersih, nyaman, aman, dan sehat bagi masyarakat dilingkungan rumah sakit.

- Faktor - faktor yang berpengaruh terhadap peningkatan keselamatan pasien dirumah sakit

\section{Iklim Organisasi}

Untuk mengukur kondisi iklim keselamatan pasien Ci rumah sakit mencakup 4 hal yang terkait, yaitu (1) kepemimpinan transformasional (di tingkat CEO/direksi RS), (2) kerjasama tim (di tingkat unit kerja), (3) kesadaran individual (di tingkat individu) serta (4) iklim keselamatan pasien (di tingkat organisasi/ RS). Pada saat ini, terjadi penurunan kualitas pelayanan kesehatan yang menyebabkan terjadinya penurunan upaya keselamatan dalam keperawatan hampir disemua Negara.

Dalam menjalankan fungsi manajernen, rnanajemen, seorang manajer diharapkan memiliki kemampuan yang cukup dalam mengorganisasikan pegawainya. Salah satu kemampuan yang dimaksud adalah kemampuan motivasi SDM yang ada. Manajer dan asisten keperawatan sebaiknya memberikan motivasi untuk menimbulkan dorongan kepada perawat. Dengan diberikannya motivasi, diharapkan perawat akan bersemangat dalam melaksanakan program patient safety. lklim organisasi memiliki hubungan yang signifikan terhadap patient safety. Maka untuk meningkatkan kualitas dan meningkatkan keselamatan dalam pelayanan kesehatan perlu dilakukan perbaikan dalam iklim organisasi. Dari segi biaya, perbaikan iklim organisasi akan menghasilkan biaya yang relatif rendah. Rendahnya biaya yang diperlukan dapat membantu rumah sakit meningkatkan efektifitas dan efisiensi biaya. lklim orgnisasi yang baik juga akan berpengaruh pada etika petugas kesehatan.

\section{Tingkat Pengetahuan}

Tingkat pengetahuan tenaga medis khususnya perawat sangatlah penting dalam meiaksanakan asuhan keperawatan. Semakin tinggi

pengetahuan perawat tentang kode etik dan hukum kesehatan maka 
semakin baik pula kinerja perawat dalam melaksanakan asuhan keperawatan. Tingkat pengetahuan yang tinggi akan mempengaruhi kinerja perawat sehingga asuhan keperawatan akan terlaksana dengan baik dan kemungkinan tidak terjadinya malpraktik atau kelalaian akan keselamatan pasien. Hal ini terjadi karena perawat atau tenaga medis telah dibekali dengan pengetahuan tentang etika dan patient safety.

\section{Penerapan Keselamatan Pasien}

Penerapan budaya keselamatan pasien dalam sebuah organisasi tidak terlepas dari peran aktif atasan (supervisor atau manajer dalam mempromosikan dan melakukan tindakan yang mendukung berjalannya proses penanaman nilai yang dianut). Budaya keselamatan yang baik dapat mengurangi risiko terjadinya kejadian yang tidak diinginkan. Maka, diperlukan pelatihan secara rutin bagi petugas medis agar benar - benar memahami budaya keselamatan pasien. Pengawasan dari atasan juga harus ditingkatkan sebagai salah satu upaya untuk menerapkan budaya keselamatan pasien. Semua itu harus didukung dengan kebijakan dari atasan dan semua petugas medis harus bisa menindaklanjuti setiap kebijakan yang dibuat. Jika semua itu dilakukan, maka budaya keselamatan pasien akan berjalan dengan baik.

\section{Aspek Komunikasi}

Komunikasi yang baik antar petugas medis dengan pasien akan memberikan dampak yang positif terhadap mutu pelayanan kesehatan di suatu rumah sakit serta dimungkinkan menurunkan kesalahpahaman apabila terjadi kecelakaan, kelalaian dan ataupun malpraktik.

Pelayanan kesehatan yang bermutu yaitu pelayanan kesehatan yang dapat memuaskan setiap pemakai jasa pelayanan sesuai dengan kode etik dan standar pelayanan yang telah ditetapkan. Pelayanan perawatan yang sesuai dengan standar memiliki dampak yang lebih besar terhadap citra pelayanan rumah sakit. 


\section{Aspek Etika}

Menurut Peraturan Pemerintah No. 32 Tahun 1996 tentang Tenaga Kesehatan, hubungan perawat dan klien merupakan subjek hukum. Pemahan perawat mengenai hukum kesehatan memberikan keyakinan kepada perawat dan menjaga klien untuk selalu berada pada jalur yang aman dengan mengikuti standing order yang telah ditetapkan oleh profesi keperawatan dari pihak rumah sakit yang bersangkutan. Standing Order merupakan pendelegasian kepada tenaga keperawatan dalam memberikan asuhan keperawatan atau pelayanan kesehatan.

Dalam melaksanakan kewajibannya sebagai tenaga medis maka harus sesuai dengan kode etik atau etika yang telah ditetapkan. Hal ini dilakukan agar tenaga medis selalu mengutamakan keselamatan pasien dan tidak seenaknya melakukan tindakan medis yang tidak sesuai dengan standar.

\section{PENUTUP}

Sejumlah program yang berada pada naungan program PKRS telah banyak dilaksanakan, misalnya advokasi, menyusun sebuah program untuk PKRS, dan melaksanakan sosialisasi tentang program PKRS kepada direktur dari Rumah Sakit Pemerintah. Pelatihan PKRS,, pengembangan, dan distribusi media, serta pengembangan model dan PKRS (Depkes RI, 2010).

Pelaksanaan promosi kesehatan rumah sakit (PKRS) sangat bermanfaat untuk menambah wawasan untuk pasien dan keluarganya, serta pengunjung di rumah sakit tentang beragam jenis penyakit serta langkah apa saja yang diperlukan untuk pencegahannya, selain itu promosi kesehatan di rumah sakit merupakan upaya rumah sakit untuk meningkatkan kemampuan pasien, keluarga dan pengunjung rumah sakit agar dapat berperan secara positif dalam usaha penyembuhan dan pencegahan terhadap penyakit sehingga dapat mempercepat proses

penyembuhan serta rehabilitasi, meningkatkan kesehatan, mencegah terjadinya penyakit, serta mengembangkan berbagai upaya untuk meningkatan kesehatan masyarakat melalui pembelajaran sesuai dengan sosial dan budaya masing-masing secara mandiri (Depkes RI, 2011). 
Selanjutnya, pelaksanaan dari promosi kesehatan berhubungan juga dengan penerapan dalam keselamatan pasien (patient safety). Terdapat beberapa aspek - aspek yang mempengaruhi berjalannya program keselamatan pasien diantaranya : iklim organisasi, tingkat pengetahuan, penerapan dalam keselamatan pasien, komunikasi, dan etika. Budaya keselamatan pasien akan tercipta apabila tenaga kesehatan memiliki pemimpin yang bersedia bekerjasama demi terlaksananya keselamatan pasien (patient safety) dan juga mau bekerjasama dalam tim untuk melakukan promosi kesehatan guna tercapainya kepuasan pasien akan pelayanan kesehatan yang diberikan oleh tenaga kesehatan di rumah sakit. 


\section{DAFTAR PUSTAKA}

Gumilang, B. (2015). Analisis Faktor Yang Mempengaruhi Implementasi Kebijakan Promosi Kesehatan Rumah Sakit (Pkrs) Di Rumah Sakit Universitas Airlangga. 1-14.

Harus, B, D (2015). Pengetahuan Perawat Tentang Keselamatan Pasien DenganPelaksanaan Prosedur KeselamatanPasien Rumah Sakit (KPRS) DiRumah Sakit Panti Waluya SawahanMalang. Jurnal Care. Vol. 3 (1). 25-32.

Iriviranty, A. (2018). Analisis Budaya Organisasi dan Budaya Keselamatan Pasien Sebagai Langkah Pengembangan Keselamatan Pasien di RSIA Budi Kemuliaan Tahun 2014. Jurnal Administrasi Rumah Sakit Indonesia,1(3).

Mudayana, A.A. (2015). Peran Aspek Etika Tenaga Medis Dalam Penerapan Budaya Keselamatan Pasien Di Rumah Sakit. Majalah Kedokteran Andalas, 37, 69 - 74.

Nurdianna, F. (2017). Pelaksanaan Promosi Kesehatan Di Rumah Sakit Universitas Airlangga Surabaya. Jurnal Promkes, 5 (2), 217-231.

Nurmalia, D., Handiyani, H., \& Pujasari, H. (2014). Pengaruh program mentoring terhadap penerapan budaya keselamatan pasien. Jurnal Manajemen Keperawatan, 2(1), 55-63.

Prahesti, M.G. (2018). Evaluasi Standar Promosi Kesehatan Di Rumah Sakit Islam Surabaya. Jurnal Promkes, Vol. 6 (1), 23-34.

Rivai, F.,dkk. (2016). Faktor Yang Berhubungan Dengan Implementasi Keselamatan Pasien Di Rsud Ajjappannge Soppeng Tahun 2015. Jurnal Kebijakan Kesehatan Indonesia. Vol. 5(4). Hal 155-156.

Simamora, R. H., \& Fathi, A. (2019). The Influence Of Training Handover Based SBAR Communication For Improving Patients Safety. Indian journal of public health research \& development, 10(9), 1280-1285.

Syam, N. S. (2017). Implementasi Budaya Keselamatan Pasien Oleh Perawat di Rumah Sakit Ibnu Sina Makassar. Fakultas Kesehatan Masyarakat,11(2), 174-180. 
Tristantia, A. D. (2018). Evaluasi Sistem Pelaporan Insiden Keselamatan Pasien di Rumah Sakit. Jurnal Administrasi Kesehatan Indonesia, 6(2), 83-94. 